\title{
AVALIAÇÃO DA PERCEPÇÃO DA DOR DURANTE A QUARENTENA ENTRE IDOSOS DE UM SERVIÇO DE REFERÊNCIA EM SAÚDE
}

Eric Lins Soeiro; UEPA; soeiro.els@gmail.com

Ana Beatriz Tavares Araújo; UEPA; biatavares60@gmail.com

Arilson Lima da Silva; UEPA: Arilson.limasilva18@gmail.com

Armando da Silva Rosa; UEPA; armandorosa9@gmail.com

Clara Danielly Campos de Carvalho Silva; UEPA; claracarvalhoo145@gmail.com

Moisés Felipe Silva da Conceição; UEPA; moisesfelipe.uepa@gmail.com

Rondinei Silva Lima; Grupo Cynthia Charone; nep@hospitalcynthiacharone.com

Cynthia Cyllene de Oliveira Charone; Grupo Cynthia Charone; cynthiacharone@yahoo.com.br

\section{RESUMO}

Introdução: Segundo a Sociedade Brasileira de Geriatria e Gerontologia (SBGG), até 50\% dos idosos provenientes da comunidade apresenta problemas dolorosos importantes. Logo, desafios assistenciais se impõem, já que idosos são suscetíveis a desequilíbrios sociais. Assim, é válido o rastreio durante isolamento social. Objetivo: Verificar a percepção dolorosa em idosos de uma instituição de referência sobre envelhecimento saudável durante o isolamento social devido ao COVID-19. Métodos: Estudo transversal descritivo com 799 indivíduos, baseado no telemonitoramento de idosos ( $\geq 60$ anos) participantes do serviço de geriatria e gerontologia do Grupo Cynthia Charone, mediante anuência assinada e os preceitos éticos da pesquisa. Resultados: Verificou-se que, do total de pacientes, 225 apresentaram dor no cotidiano às vezes (20\%) ou frequentemente $(9,6 \%)$ e 199 tiveram seu nível de dor estratificado em 1-3 (2,3\%), 4-5 (11,5\%), 6-8 (16,8\%) ou 9-10 $(2,3 \%)$. Quanto à realização de atividades sem ajuda, 86,4\% afirmam ter dificuldade, sendo que $76,5 \%$ assinalaram "frequentemente". Quanto à dor ao levantar ou subir escadas $30,4 \%$ referiram dor às vezes $(10,8 \%)$ ou frequentemente $(19,6 \%)$. Por fim, $77,2 \%$ dos individuos referiu que manteve a saúde estável durante o isolamento social, enquanto 17,1\% referiu piora. Conclusão: Observou-se que parcela considerável de pacientes do Grupo Cinthya Charone apresentou queixas de dor, predominantemente de nível intermediário a alto (4-8), sendo que a maioria referiu manutenção ou piora dos sintomas durante o isolamento social com a redução das atividades multiprofissionais. Assim, deve-se atentar para sintomas álgicos e estratégias de combate, já que interferem significativamente na qualidade de vida do idoso.

Palavras-chave: Saúde do idoso; Dor crônica; Isolamento social; Coronavirus. 